\title{
EL PATRIMONIO MONUMENTAL BICENTENARIO Y LA RUTA TURÍSTICA "LIBERTADORA"
}

Luis Rubén Pérez Pinzón 


\section{THE BICENTENNIAL MONUMENTAL HERITAGE AND THE "LIBERATING" TOURIST ROUTE}

\section{RESUMEN}

Colombia ha encontrado en el turismo monumental una alternativa de desarrollo como parte de los emprendimientos culturales y la redefinición de la identidad nacional por parte de los viajeros internos. Para tal fin, han sido creadas rutas turísticas que articulan los conjuntos monumentales con los pueblos patrimonio, que en el caso del norte de Boyacá y el sur de Santander, cumplen el propósito de resignificar la historia y los imaginarios nacionales asociados con la independencia y la liberación que antecedieron a la fundación del Estado republicano vigente. Como parte del bicentenario de esas gestas, en 2017 fueron creadas las rutas turísticas de la "Memorias de la Independencia" y "Libertadora" por parte del Ministerio de Comercio, Industria y Turismo (MinCIT), las cuales sirven como antesala de las conmemoraciones bicentenarias y son motivo coyuntural para la conservación de los monumentos culturales edificados como parte de esas conmemoraciones en décadas y siglos anteriores. A partir de los planes de desarrollo turístico promovidos por el MinCIT, la exploración literaria del Semillero Silencio - UNAB y el trabajo de campo del Semillero en Turismo Alternativo y Sostenible de la Universidad Industrial de Santander (Tas - UIS), son identificadas las fortalezas patrimoniales y los destinos territoriales que contribuirán desde el turismo patrimonial al desarrollo regional y sostenible de los circuitos turísticos nororientales.

Palabras clave: Turismo, ruta turística, Boyacá, Socorro, Colombia.

\section{AUTORES}

\section{Luis Rubén Pérez Pinzón}

Docente investigador del Departamento de Estudios

Sociohumanísticos y del Pregrado en Literatura

Integrante del grupo de investigación Transdisciplinariedad, Cultura y

Política (TCP)

Docente - Tutor del Semillero de Investigación en Literatura del Estado Nación y el Conflicto Interno (Silencio) de la Universidad Autónoma de

Bucaramanga

Correo electrónico: Iperez14@unab.edu.co.

\section{ABSTRACT}

Colombia has found in heritage tourism an alternative for development as part of the cultural undertakings and the redefinition of national identity by the travellers within the country. Because of this reason, tourist routes, that articulate the monumental complexes with the "heritage towns", have been created. In the case of the north of Boyacá and the south of Santander, these routes fulfill the purpose of resignifying the history and the national imaginaries associated with independence and the liberation that preceded the foundation of the current republican state.

As part of the bicentennial of these deeds, in 2017 the tourist routes of "independence" and "liberation" were created by the Ministry of Commerce, Industry and Tourism (MinTIC) which serve as a prelude to the bicentennial commemorations. They are a circumstantial motive for the conservation of the cultural monuments built as part of those commemorations in previous decades and centuries.

Based on the tourism development plans promoted by Min$\mathrm{CIT}$, the literacy exploration of the research group Semillero Silencio, Unab, and the fieldwork of the Tas-Uis, heritage strengths and territorial destinations are identified which will contribute from heritage tourism to regional and sustainable development of the northeast tourist circuits.

Keywords: Tourism, tourist route, Boyacá, Socorro, Colombia. Recibido: 14 de septiembre 2018
Aprobado: 15 de octubre 2018 


\section{INTRODUCCIÓN}

El turismo monumental es la visita contemplativa y reconstructiva al paisaje cultural de un territorio que contiene bienes de interés tangible que evidencian la presencia exploratoria (un día), expansionista (un año), colonial (un siglo) o civilizatoria (un milenio) de una comunidad humana intangible (Heredia 2004). Bienes que datan de diferentes temporalidades y pueden estar ubicados dentro de un centro urbano (conjuntos palaciegos, conjuntos religiosos [iglesia, monasterio, convento, cementerio]), en su periferia (castillos, fortalezas, reales sitios), jurisdicción (caminos, yacimientos, ermitas) o frontera rural (puentes, murallas) (Jiménez, 2002). Esos vestigios humanos fueron reconocidos por la Conferencia General de la Organización de las Naciones Unidas de 1972 y por la Ley General de Cultural de Colombia de 1997, como parte del patrimonio cultural tangible de cada pueblo, siendo protegidos y salvaguardados como bienes que evidencian su memoria, tradiciones y expresiones culturales para la posteridad.

Los legados tangibles se constituyen en las principales razones de visita a las comunidades humanas que salvaguardan y conservan sus monumentos como evidencias de la grandeza de su pasado y piezas únicas para su nación, así como se constituyen en fuentes seguras de ingresos al ser reclamadas y vivenciadas por el resto de los humanos dispuestos a invertir su tiempo, ahorros, lecturas y atención al visitarlos (Fernández y Guzmán, 2004). La interacción con esas mismas comunidades, muchas de las cuales no son descendientes ni herederas directas de los vestigios monumentales del pasado, conllevan a que el visitante interactúe con los legados intangibles de las comunidades del presente al vivenciar sus tradiciones (gastronómicas, artesanales, recreativas) y expresiones artísticas (musicales, teatrales, literarias) (Pérez, 2017); reafirmándose así, los prin- cipios de la Carta Internacional en Turismo Cultural (1999), según la cual, la migración humana contribuye al estudio y promoción de los sitios o monumentos de interés artístico, folclórico o peregrinante, y consigo, al reconocimiento de las representaciones artísticas, festivas o culturales de las comunidades receptoras (Pérez, 2015).

El interés por el turismo cultural, y específicamente por la promoción de los "pueblos" que conservan vestigios del patrimonio hispanocatólico heredado del período colonial europeo (siglos XVI-XIX), se constituyó en política pública de Colombia al adoptarse la Ley 300 de 1996, conocida como "Ley General de Turismo". La reforma a esa ley, con la Ley 1558 de 2012 permitió consolidar las dependencias, fuentes de financiación y programas que el MinCIT había promovido para fomentar el turismo nacional en los mercados y ferias internacionales, a partir de campañas que promocionaran los atributos particulares de la marca país, y especialmente, la oferta de sus pueblos patrimonio como un producto turístico que revelara la identidad y diversidad de los colombianos.

El cambio de campaña y las mejoras a la marca Colombia a finales de 2017, a la par del inicio de la época vacacional de mayor movilización del turismo interno, resultaron propicias para que el MinCIT promoviera el fomento de un conjunto de rutas turísticas que cumplían las metas pendientes de la Ley de Turismo de 1996, pues articulaban todas las estrategias y programas turísticos promovidos por el gobierno colombiano a través del Fondo Nacional de Turismo (Fontur), así como reafirmaban la consolidación de la industria del turismo como generadora de desarrollo y sostenibilidad para las economías regionales.

Para demostrar las características e importancia que tendrán desde 2018 las rutas turísticas "Memorias de la independencia" y "Libertadora" para el desarrollo regional de los departamentos de Boyacá y San- 
tander, a continuación se presentan los elementos del patrimonio monumental con los cuales el pueblo patrimonio de El Socorro se articula a los circuitos, caravanas y corredores turísticos promovidos para la conmemoración del bicentenario de la liberación neogranadina y la creación de la República de Colombia; constituyéndose en un referente necesario para la articulación de las rutas regionales y el desarrollo turístico de ambas regiones.

Lo anterior, entendiendo por recursos turísticos a los diferentes tipos de bienes de interés cultural y patrimonial como son "...plazas, vías, monumentos, construcciones y otros que deban desarrollarse con sujeción a planes especiales, adquirirse por el Estado o preservarse, restaurarse o reconstruirse" (Ley 300,1996 art. 23).

La metodología empleada corresponde a un estudio con enfoque cualitativo y se constituye en producto resultado de un proyecto de investigación financiado por la Universidad Industrial de Santander (Cód. UIS5007). Para su desarrollo, se emplearon técnicas de análisis de contenidos y contraste de fuentes documentales con la ayuda de los estudiantes del Semillero en Literatura Silencio de la UNAB, previa identificación de los destinos urbanos más importantes, en la que se emplearon técnicas de observación, entrevistas, trabajo de campo y construcción de bases de datos con el apoyo de los estudiantes del Semillero en Turismo Alternativo y Sostenible de la Universidad Industrial de Santander (Tas-UIS).

\section{CÍRCULOS, CARAVANAS Y CORREDORES TURÍSTICOS A TRAVÉS DEL SOCORRO}

Uno de los territorios beneficiados con las campañas turísticas del Estado colombiano ha sido el círculo metropolitano del Socorro dispuesto por la Ley de Turismo (1996), el cual hizo parte de la caravana "Sueños de los Comuneros" (2006) y fue formalizado como el Corredor Turístico del Nororiente (2016). Su propósito y oferta desde finales de 2017 han estado asociados con la ruta "Memorias de la Independencia", lo cual implica que el visitante vaya tras las huellas de los insurgentes comuneros y libertadores al visitar los pueblos patrimoniales de El Socorro, San Gil, Barichara, Curití y Girón, e incluso la procera Charalá de mejorarse su acceso vial. Dicha ruta consolida el turismo en el centro de Santander y se articula plenamente a la "Ruta Libertadora" promovida en el norte del Departamento de Boyacá, limítrofe con Santander, para los viajeros que recorren el país desde la capitalina Bogotá hasta la región caribe (Tabla 1).

La ruta "Memorias de la Independencia" desde sus orígenes como círculo, caravana y corredor ha tenido como eje receptor y articulador de las políticas turísticas al municipio y ciudad de El Socorro, población tradicional turística de Santander, cuyos 30.000 habitantes se han dado a sí mismos el título y condición de "Ciudad Histórica y Cultural de Colombia". Si bien otras ciudades cumplirían mejor esos atributos como las declaradas patrimonio de la humanidad (Cartagena y Mompox) o las ciudades que han servido como capitales del país desde el período colonial (Santafé, Tunja y Villa de Leyva), los socorranos han remarcado su diferencial turístico, histórico y cultural al promover al municipio como "Cuna de la libertad de América"; condición justificada por ser la ciudad capital de la provincia del Socorro donde se gestaron los movimientos rebeldes (1781-1782), independentistas (1810-1811) y libertadores (1817-1819) más importantes del nororiente colombiano (Martínez y Pérez, 2017).

\section{EL SOCORRO: ENTRE LA RUTA DE "LA INDEPENDENCIA" Y LA "LIBERTADORA"}

A diferencia de la historia turística que centraliza sus estudios en la cronología de la creación artística, usos sociopolíticos y conservación del objeto monumental (representaciones históricas a través 
Tabla 1.

Transformaciones de las rutas turísticas de Colombia por Boyacá y Santander

\begin{tabular}{|c|c|c|c|}
\hline $\begin{array}{c}\text { Círculos turísticos } \\
\text { metropolitanos, } 1996\end{array}$ & $\begin{array}{l}\text { Caravanas turísticas, 2002- } \\
2006\end{array}$ & $\begin{array}{l}\text { Corredores turísticos, } \\
\text { 2016-2017 }\end{array}$ & $\begin{array}{c}\text { Rutas turísticas, } \\
\text { 2017-2018 }\end{array}$ \\
\hline $\begin{array}{l}\text { Socorro (conformado por } \\
\text { los municipios de San Gil, } \\
\text { Barichara y Charalá en el } \\
\text { departamento de Santander) }\end{array}$ & $\begin{array}{l}\text { - Tradiciones del oro y el } \\
\text { tabaco } \\
\text { - Pioneros de la } \\
\text { independencia } \\
\text { - Sueños de los comuneros }\end{array}$ & $\begin{array}{l}\text { Nororiente (Departamentos } \\
\text { de Santander y Norte de } \\
\text { Santander) }\end{array}$ & $\begin{array}{l}\text { Memorias de la } \\
\text { Independencia. Destinos } \\
\text { turísticos: Socorro, San Gil, } \\
\text { Barichara, Curití y Girón } \\
\text { (Santander). Esta ruta tiene } \\
287 \text { establecimientos de } \\
\text { alojamiento formalizados, } \\
\text { que ofrecen } 3.430 \\
\text { habitaciones y } 6.775 \text { camas } \\
\text { disponibles. }\end{array}$ \\
\hline $\begin{array}{l}\text { Boyacá (Paipa, Duitama, } \\
\text { Tibasosa, Nobsa, Monguí, } \\
\text { Sogamoso, Iza, Tota, } \\
\text { Aquitania, Tunja, Villa de } \\
\text { Leyva, Ráquira, Sáchica, } \\
\text { Chiquinquirá, Tópaga, } \\
\text { Mongua y Gámeza) }\end{array}$ & $\begin{array}{l}\text { - Tradiciones del oro y el } \\
\text { tabaco } \\
\text { - Pioneros de la } \\
\text { independencia } \\
\text { - Termales muiscas }\end{array}$ & $\begin{array}{l}\text { Central (Departamentos } \\
\text { de Bogotá, Cundinamarca, } \\
\text { Boyacá, Huila y Tolima) }\end{array}$ & $\begin{array}{l}\text { Libertadora. Destinos } \\
\text { turísticos: Chiquinquirá, } \\
\text { Ráquira, Villa de Leyva, } \\
\text { Tunja, Paipa, Nobsa, } \\
\text { Monguí y Tópaga (Boyacá). } \\
\text { En esta ruta hay } 452 \\
\text { establecimientos de } \\
\text { alojamiento y hospedaje, que } \\
\text { ofrecen } 5.880 \text { habitaciones y } \\
10.494 \text { camas disponibles. }\end{array}$ \\
\hline
\end{tabular}

Construcción propia basada en Ley 300 de 1996, MinCIT (2003), MinCIT (2017a) y MinCIT (2017b).

del tiempo), el turismo histórico propicia la reconstrucción y comprensión de las representaciones turísticas, entendidas como "un fenómeno que reclama profusas indagaciones en tanto estímulos fundamentales de la visita, frecuentemente más vigorosos y dinámicos que los mismos recursos turísticos" (Navarro, 2015, p. 353). De allí que la Red Turística de Pueblos Patrimonio (RTPP) en cumplimiento de la política pública en turismo cultural ha establecido los atributos y características que dan valor de marca y garantizan una experiencia turística integral y significativa, al seleccionar desde 2010 los Pueblos Patrimonio identitarios de Colombia, a la par de establecer corredores y rutas turísticas que garantizan la llegada de visitantes externos y el desarrollo socioeconómico de los receptores locales.
En lo concerniente a los pueblos patrimonio asociados con los procesos de insurrección e independencia del colonialismo español, si bien el Socorro "es reconocido por ser centro de la revolución de los comuneros, que conllevó a la independencia del imperio español", donde "fueron firmadas las primeras Actas de Independencia y Constitución" (MinCIT - Fontur, 2016, p. 71), los atributos asignados por la RTPP la limitan a ser visitada solo como "una villa de la época de la colonia" y ejemplo patrimonial de las "memorias de la independencia". A pesar de lo descrito, del culto a la heroína guerrillera Antonia Santos, auxiliadora del ejército libertador de Venezuela, quien cuenta en la ciudad con placas, estatuas, monumento, sala de la casa-museo, parque, barrio y biblioteca (MinCIT Fontur, 2016 p. 46), para perpetuar su nombre entre 
los mártires de la liberación independentista, y de la importancia estratégica que tuvieron las guerrillas y mártires patriotas de la batalla de Pienta (Agosto 4 de 1819) para el triunfo de los insurgentes libertadores en Vargas y Boyacá, solo al pueblo de Guaduas se le ha asignado el privilegiado atributo de "Territorio revolucionario, líder de la insurrección en contra de la corona española" (MinCIT -Fontur, 2016, p. 63).

Ante el desconocimiento del accionar insurgente del Socorro y de otros pueblos protagónicos de la Independencia como Mompox, Monguí, Villa de Leyva y Honda, Guaduas solo oferta como accionar revolucionario e insurgente estatuas, plazas y museos que rememoran las acciones de la heroína local Policarpa Salavarrieta ("Pola") (1819) y el circunstancial accionar guerrillero del comunero socorrano José Antonio Galán contra las instituciones virreinales en esa villa (1781); con lo cual, la historia revolucionaria de Guaduas está directamente conectada con las acciones insurgentes y libertadoras concebidas o promovidas por los independentistas del Socorro. Estos criterios no fueron tenidos en cuenta por los investigadores y especialistas socioculturales contratados por el MinCIT - Fontur al formular los planes estratégicos en desarrollo turístico de Colombia, al analizar los atributos de los pueblos patrimonio, ni al definir los temas de las rutas turísticas que los interrelacionan.

A partir de la reflexión y discusión de esas dinámicas turísticas y los resultados de las investigaciones formativas realizadas con los semilleros integrados a los procesos de exploración de fuentes literarias y de caracterización de destinos turísticos locales, se planteó como alternativa de orientación para los visitantes con intereses turísticos culturales el reafirmar la importancia de los discursos y la monumentalidad asociada con la historia revolucionaria desde la monumentalidad artística y el patrimonio cultural que se conservan en el Socorro.
Hoy es posible recorrer las calles del centro histórico de El Socorro para identificar libremente los elementos iconográficos que evidencian los propósitos fundacionales de cada monumento, la ubicación, los responsables que permiten o limitan el acceso, las condiciones actuales del atractivo y la existencia de señalética para ubicar cada uno de los mismos, acorde a los diferentes momentos en que se ha manifestado el "alma" revolucionaria de la ciudad del Socorro y los socorranos (Tabla 2). En adición, es reafirmada esa condición al considerarse -durante la inauguración del VII Encuentro de la Red de Pueblos Patrimonio en Colombia- que El Socorro es el destino histórico y cultural que "resguarda gran parte de la gesta libertadora", y consigo, "solo la cultura y la historia es lo que nos hace trascender, nos hace coexistir en el tiempo" (El Tiempo, 2017).

El $58 \%$ de todos los atractivos históricos urbanos de El Socorro se encuentra en espacios públicos de acceso libre o institucional, en su mayoría en los parques y plazas, factor que conlleva a que las estatuas sin pedestal elevado estén descuidadas y deterioradas al ser golpeadas, desgastadas y pintadas por transeúntes y deportistas urbanos. A diferencia de la "Ruta Libertadora" que se concentra en la campaña libertadora, y en especial en el campo monumental de la Batalla de Boyacá (Fajardo, 1983), El Socorro no cuenta con monumentos en forma de busto, ecuestres, ni en pedestal en honor a Simón Bolívar; siendo exaltados con placas, bustos o monumentos elevados solo los próceres, mártires y "libertadores" oriundos de la "antigua provincia del Socorro" (Rodríguez, 1963) que participaron en las campañas y batallas del dictador, pacificador, libertador y primer ciudadano de Colombia. 
Tabla 2.

Recursos turísticos asociables con la "ruta libertadora" en El Socorro (fragmento)

\begin{tabular}{|c|c|c|c|c|}
\hline Recorridos y atractivos turísticos & Ubicación & Accesibilidad & Estado & Señal \\
\hline 2. Independencia (1810-1840) & & & & \\
\hline 2.1 Convento de los capuchinos & Cra. $08, \mathrm{Cll} 14$ & Privada-religiosa & Restaurado & Fontur \\
\hline $\begin{array}{l}\text { 2.2 Monumento al bicentenario } \\
1810\end{array}$ & Cra. 8, Cll 12 & Pública-libre & Descuidado & Talla \\
\hline $\begin{array}{l}\text { 2.3 Casa de la cultura-museo A. } \\
\text { Santos }\end{array}$ & Cra. 12, Cll 14 & Privada-museo & Conservado & Fontur \\
\hline 2.4 Mártires del Socorro 1782-1822 & Cra. 12, Cll 14 & Pública-libre & Conservado & Placa \\
\hline 2.5 Casa natal can. Andrés M. Rosillo & Cra. 15, Cll 16 & Privada- residencial & Conservado & Fontur \\
\hline $\begin{array}{c}\text { 2.6 Panteón de los próceres / capilla } \\
\text { de la Inmaculada Concepción }\end{array}$ & Cra. 15, Cll 16 & Privada-religiosa & Conservado & Fontur \\
\hline 2.7 Parque de la Independencia & Cra. 15, Cll 15 & Pública-libre & Restaurado & Fontur \\
\hline 2.8 Estatua Antonia Santos & Cra. 14, Cll 15 & Pública-libre & Descuidado & Fontur \\
\hline 2.9 Plaza San Victorino & Cra. $15, \mathrm{Cll} 13$ & Pública-libre & Descuidado & Fontur \\
\hline 2.10 Estatua coronel Pedro Monsalve & Cra. $15, \mathrm{Cll} 13$ & Pública-libre & Conservado & Placa \\
\hline 2.11 Mártires del Socorro en 1816 & Cra. 15, Cll 13 & Pública-libre & Conservado & Placa \\
\hline 2.12 Estatua General Antonio Obando & Cra. $16, \mathrm{Cll} 13$ & Pública-libre & Conservado & Placa \\
\hline $\begin{array}{l}2.13 \text { Monumento del centenario a. } \\
\text { Santos y M. Beltrán / Parque } \\
\text { A. Santos }\end{array}$ & Cra. 14, Cll 10 & Pública-libre & Restaurado & Fontur \\
\hline $\begin{array}{l}\text { 2.14 Colegio Universitario del } \\
\text { Socorro }\end{array}$ & Cra. 13, Cll 5 & Pública-libre & Conservado & Fontur \\
\hline 2.15 Estatua José Lorenzo Plata & Cra. 13, Cll 5 & Pública-libre & Conservado & Placa \\
\hline 2.16 Estatua Francisco P. Santander & Cra. 13, Cll 5 & Pública-libre & Conservado & Placa \\
\hline 2.17 Quintas de Fominaya & Vía a Bogotá & Privada-comercial & Conservado & Fontur \\
\hline 2.18 Biblioteca B. Antonia Santos & Cra. 06, Cll 6 & Pública-institucional & Conservado & Fontur \\
\hline
\end{tabular}

Fuente: Elaboración propia 


\section{CONCLUSIONES}

Las estrategias francesas, españolas y mexicanas de reconocimiento, protección y promoción de los pueblos patrimoniales más representativos de su historia, cultura y tradiciones nacionales han sido adaptadas en Colombia a través de la Red Turística de Pueblos Patrimonio. Poblaciones con características y proyecciones turísticas propias, que al ser articuladas y redimensionadas desde los temas y motivos que reafirman la identidad nacional han conllevado a la conformación de rutas turísticas coyunturales como la de "La Independencia" y "Libertadora", con las cuales se promueven nuevos modelos de desarrollo económico desde el turismo cultural, así como se delimitan los lugares de conmemoración y congregación con motivo del bicentenario de la liberación patriota y la creación de la República de Colombia.

Dichas rutas en un contexto de turismo durante el posconflicto fueron resultado de experiencias turísticas, conmemorativas y de fomento regional como es el caso de los corredores turísticos que articularon los destinos departamentales o regionales más golpeados y empobrecidos durante los años de guerra irregular, las caravanas turísticas con las que se afrontó la amenaza de los grupos insurgentes al hacer presencia las autoridades y los ciudadanos en los territorios vedados o prohibidos por los ejércitos revolucionarios, así como la consolidación de la propuesta de circuitos turísticos metropolitanos que la primigenia Ley de Turismo de 1996 había establecido, y con la que se esperaba conformar regiones turísticas asociadas con los pueblos declarados a mediados del siglo XX como monumentos nacionales.

En el caso del Municipio de El Socorro y la Provincia Comunera a la que sirve como ciudad capital, su patrimonio cultural monumental se caracteriza por contar con vestigios de las causas, conflictos internos y consolidación del periodo de insurrección del régimen colonial español, constituyendo esos vestigios en "Memorias de la Independencia". Sin embargo, sus pobladores, gestores culturales y autoridades municipales durante dos siglos de vida republicana se han preocupado por construir, conservar y promover una monumentalidad que exalta a sus héroes y mártires locales o provinciales, minimizando el papel de las grandes personalidades libertadoras erigidas en monumentos a lo largo del campo de Batalla. De tal modo, han hecho de su patrimonio monumental una alternativa para resaltar en la memoria regional a los combatientes menospreciados por el relato oficial captado por los "generales libertadores", así como un destino cultural divergente al guion turístico que caracterizará la ruta libertadora y la conmemoración bicentenaria del nacimiento libertario de la República a partir de 2019.

\section{REFERENCIAS}

Fajardo, M. (1983). Fuentes históricas y documentales para el estudio del culto al Libertador Simón Bolívar. Anuario Colombiano de Historia Social y de la Cultura, (11), 351-361.

Fernández, G. y Guzmán, A. (2004). Rutas turísticas a partir del patrimonio industrial. Nuevos productos en viejas estructuras. Turismo y Sociedad, (1), 40-52. Recuperado de https://goo.gl/do7JwS.

Heredia, W. (2004). Patrimonio cultural: lo intangible se hace intangible. Turismo y Sociedad, (3), 53-154. Recuperado de https://goo.gl/yT9Bs9.

Jiménez, L. (2002). Leer la ciudad: Establecer un diálogo entre el sujeto moral y el patrimonio arquitectónico. Turismo y Sociedad, (1), 80-86. Recuperado de https://goo.gl/cmgEGj.

Ley 300 de 1996, Ley General de Turismo. Diario Oficial de Colombia, Bogotá, Senado de Colombia, 
1996. Recuperado de https://goo.gl/hexfMz.

Martínez, L. y Pérez, L. (2017). Turismo literario y Santandereanidad. Bucaramanga, Colombia: UIS.

Ministerio de Comercio de Industria y Turismo (MinCIT) y Fondo Nacional de Turismo (Fontur). (2016). "Una Nueva Historia": Plan estratégico de desarrollo turístico 2016-2025. El Socorro, Santander: MinCIT-Fontur.

Ministerio de Comercio, Industria y Turismo (MinCIT). (2003). Caravanas turísticas, Vive Colombia. Recuperado de https://goo.gl/Wt9wTk.

Ministerio de Comercio, Industria y Turismo (MinCIT). (2017a). 12 corredores turísticos serán el motor de las regiones. Recuperado de https://goo.gl/DBg5pe

Ministerio de Comercio, Industria y Turismo (MinCIT). (2017b). Cerca de 10000 hoteles están listos para ti en las 15 rutas turísticas de la campaña "Es el momento de Colombia. Seguro te va a encontrar". Recuperado de https://goo.gl/1xnuuu

Navarro, D. (2015). Recursos turísticos y atractivos turísticos: conceptualización, clasificación y valoración. Cuadernos de turismo, (35), 335-357.

Pérez Pinzón, L. (2017). Turismo cultural en Colombia. Bucaramanga, Colombia: UIS.

Pérez, Y. (2015). La imagen del turismo cultural en Cuba percibida por el mercado español. Turismo y Sociedad, (16), 67-84.

Rodríguez Plata, H. (1963). La antigua provincia del Socorro y la independencia. Bogotá, Colombia: Academia de Historia de Colombia.

-----. Turismo monumental. (29 enero de 1997). El Tiempo. Recuperado de https://goo.gl/Bj3Rna 